\title{
Extending the scope of mitral valve repair in active endocarditis
}

\author{
Laurent de Kerchove, MD, ${ }^{\text {a }}$ Joel Price, MD, MPH, ${ }^{\mathrm{a}}$ Saadallah Tamer, MD, ${ }^{\mathrm{a}}$ David Glineur, MD, PhD, ${ }^{\mathrm{a}}$ \\ Mona Momeni, MD, ${ }^{\mathrm{b}}$ Philippe Noirhomme, MD, ${ }^{\mathrm{a}}$ and Gebrine ElKhoury, $\mathrm{MD}^{\mathrm{a}}$
}

Objective: During the last 2 decades, we have applied a repair-oriented surgical approach to patients with active mitral valve endocarditis. We retrospectively analyzed the long-term outcomes with this repair-oriented approach.

\begin{abstract}
Method: Between 1991 and 2010, 137 patients underwent operation for active mitral valve endocarditis; of these, 109 patients $(80 \%)$ had mitral valve repair and represent the study cohort. Repair techniques without patch extension (no-patch techniques) include triangular or quadrangular resection $(\mathrm{n}=49)$, sliding plasty $(n=24)$, neochordae $(n=18)$, chordal transfer $(n=12)$, and others $(n=5)$. Repair techniques using patch extension (patch techniques) included pericardium $(\mathrm{n}=42)$, tricuspid autograft $(\mathrm{n}=8)$, flip-over technique $(n=7)$, and partial mitral valve homograft $(n=5)$. Patches were used in 67 patients $(61 \%)$. Ring annuloplasty was performed in 60 patients, and a pericardial band was used in 13 patients. Clinical and echocardiographic follow-up were performed. Median follow-up was 48 months.
\end{abstract}

Results: Hospital mortality was $16 \%$. At 8 years, overall survival was $62 \% \pm 10 \%$ with no differences between patients with or without patch repair $(P=.5)$. Freedom from mitral valve repair failure was $81 \% \pm 14 \%$ in patients with patch repair and $90 \% \pm 10 \%$ in patients without patch repair $(P=.09)$. The rate of thromboembolic or bleeding event was $1 \%$ per patient-year, and the rate of endocarditis recurrence was $0.3 \%$ per patientyear. Univariable predictors of mortality were age more than 70 years $(P<.0001)$, perivalvular abscess $(P=.002)$, diabetes mellitus $(P=.0002)$, and renal failure $(P=.04)$. Predictors of repair failure were renal failure $(P=.035)$ and perivalvular abscess $(P=.033)$.

Conclusions: In active mitral valve endocarditis, a repair-oriented surgical approach achieves a reparability rate of $80 \%$ with acceptable morbidity and good long-term results. The use of patch techniques offers a durability rate that approximates the rate obtained with the no-patch techniques. (J Thorac Cardiovasc Surg 2012;143:S91-5)

In native valve infective endocarditis (IE), the mitral valve (MV) is the most frequently affected $(40 \%-50 \%$ of the cases). ${ }^{1}$ There are several conceptual advantages of valve repair versus replacement in the setting of mitral IE. Multiple authors have advocated MV repair for IE since Dreyfus and colleagues ${ }^{2}$ published their initial series in 1990. In a meta-analysis, Feringa and colleagues ${ }^{3}$ showed that MV repair in the setting of IE was associated with good clinical in-hospital and long-term results. However, the reported rate of MV repair was only $40 \%$ for this indication, in comparison with $90 \%$ or greater for degenerative disease. The

\footnotetext{
From the Divisions of Cardiothoracic and Vascular Surgery, ${ }^{\mathrm{a}}$ and Anesthesiology, ${ }^{\mathrm{b}}$ Université Catholique de Louvain, Cliniques Universitaires Saint-Luc, Brussels, Belgium.

Disclosures: Laurent de Kerchove, Joel Price, Saadallah Tamer, David Glineur, Mona Momeni, Philippe Noirhomme, MD, and Gebrine ElKhoury have nothing to disclose with regard to commercial support.

Presented at The American Association for Thoracic Surgery Mitral Conclave, New York, New York, May 5-6, 2011.

Received for publication May 15, 2011; revisions received Dec 26, 2011; accepted for publication Jan 16, 2012; available ahead of print Feb 3, 2012

Address for reprints: Laurent de Kerchove, MD, Division of Cardiothoracic and Vascular Surgery, Cliniques Universitaires St-Luc, Avenue Hippocrate 10, 1200 Brussels, Belgium (E-mail: laurent.dekerchove@uclouvain.be). $0022-5223 / \$ 36.00$

Copyright (c) 2012 by The American Association for Thoracic Surgery doi:10.1016/j.jtcvs.2012.01.049
}

lower repair rate for IE is likely related to the type of lesions encountered and patient comorbidities. Large vegetations, multiple lesions, and annular abscess are all challenging to repair, and the classic techniques used in degenerative disease may be inappropriate in such situations. Moreover, patients with active IE commonly present in unstable conditions, which may influence the surgeon to perform an expeditious replacement instead of a difficult repair.

During the last 2 decades, our surgical approach toward active IE has evolved as predominantly repair oriented. This was characterized by an early intervention, a radical resection of the lesion, and an aggressive attitude toward valve repair using biological patch material to extend the spectrum of patients eligible to undergo valve repair.

The purpose of the current study was to analyze the longterm results achieved with this approach. In addition, we examined the durability of patch repair techniques compared with more classic repair techniques to determine if their use was justified.

\section{PATIENTS AND METHODS \\ Patient Selection}

Only patients undergoing operation during the active phase of native MV endocarditis were included. Active IE was defined as the period of time from diagnosis to completion of antibiotic therapy. Any patients 


\section{Abbreviations and Acronyms \\ $\mathrm{IE}=$ infective endocarditis \\ $\mathrm{MR}=$ mitral regurgitation \\ $\mathrm{MV}=$ mitral valve}

undergoing operation after completion of antibiotic therapy (delayed surgery) were excluded. From 1991 to 2010, 137 patients underwent operation for active MV endocarditis at the Cliniques Universitaires Saint-Luc. Of these patients, $109(80 \%)$ had MV repair and comprise the study cohort. Preoperative patient characteristics, intraoperative data, and immediate postoperative course were obtained from hospital records and operative notes (Table 1). This study was approved by the institutional ethics review board, and the need for written informed consent was waived for this study. The first half of this patient cohort has been described by the authors. ${ }^{4}$

\section{Timing of Surgery}

Indications for surgery were evaluated by a multidisciplinary team and included MV dysfunction with heart failure, IE caused by fungal or other highly resistant organism, annular abscess, recurrent emboli, persistent vegetation or fever despite appropriate antibiotics therapy, and mobile vegetation larger than $10 \mathrm{~mm} .{ }^{5}$ Timing for surgery depended on the indication and severity of clinical and echocardiographic findings. Early surgery was favored to preserve tissues from further destruction and to increase possibilities of MV repair. The presence of stroke did not contraindicate early surgery. However, surgery was delayed in case of stroke with severe neurologic dysfunction (eg, unconsciousness) or with hemorrhagic complication. With increasing experience in MV repair for active IE, we progressively expanded the indication for "early" surgery to include patients presenting with severe mitral regurgitation (MR) but no other complication. In those patients, surgery was performed electively before completion of antibiotic therapy.

As previously reported, the median delay between diagnosis and surgery has decreased since the early period of the study. ${ }^{4}$ In the last 5 years, the median delay was 9 days and $75 \%$ of the patients underwent operation within 2 weeks after diagnosis.

\section{Surgical Techniques}

All patients underwent operation via a median sternotomy. The MV was exposed via a left atriotomy. A thorough valve analysis was performed to identify IE lesion and the presence of concomitant degenerative or rheumatic lesions. Vegetations were resected with caution to preserve noninfected tissues to maximize the possibility of valve repair. The leaflet free margin and normal native chordae were preserved whenever possible.

The repair techniques are listed in Table 1. Posterior and commissural valve defects were generally primarily closed using triangular or quadrangular resection and sliding techniques. In case of a large defect, limited amount of native tissues, or resection of annular abscess or calcification, the posterior leaflet and commissures were repaired with patch techniques. Anterior valve defects were generally repaired using patch techniques to avoid reduction of its surface.

A variety of patches were used for leaflet and annulus repair, each type having a specific indication. Autologous and bovine pericardium were the most frequently used patches. Untreated autologous pericardium was typically used to repair leaflet perforation. Glutaraldehyde-treated autologous pericardium and bovine pericardium, both offering the advantage of easier manipulation, were used for more complex repair, such as free margin destruction repair. In those cases, the neo free margin was suspended with native chordae transfer or artificial chordae. Bovine pericardium was used in cases in which autologous pericardium was not readily available, such as reoperative surgery. After resection of the posterior annulus for abscess or calcification, atrioventricular junction was repaired by a Teflonreinforced U-stitch or a bovine pericardial patch covering the area of resection. When necessary, this pericardial patch was folded on its atrial side and used to reinsert and extend the posterior leaflet. Bovine pericardium was also used to repair the mitral-aortic continuity after abscess resection.

Three other types of patch technique were used for specific lesions. The tricuspid valve autograft patch was used to repair large commissural defects. The original technique was modified by adding 2 artificial chordae on the tricuspid autograft free margin to partially relieve the tension on the tricuspid papillary muscle suture. ${ }^{6}$ The flip-over technique (ie, transfer of $\mathrm{P} 2$ to A2) was used to repair a defect of the anterior leaflet A2 segment. Finally, parts of the MV homograft have been used to reconstruct large posterior valve defects or to repair the mitral-aortic continuity. For posterior valve reconstruction, a posterior MV homograft was inserted by first implanting its anterior and posterior papillary muscle onto the corresponding native papillary muscle and then suturing the leaflet tissue in place. Commissures were closed by a few millimeters to initiate coaptation. After resection of the mitral-aortic continuity due to an abscess complicating aortic valve endocarditis, the aortic valve was replaced with an aortic valve homograft. The mitral-aortic continuity was reconstructed using the anterior mitral leaflet of the aortic valve homograft. The anterior mitral homograft valve was sutured with a running 4-0 polypropylene suture to the base or body of the native anterior MV.

In addition to repair of the IE lesion, any degenerative rheumatic lesion was addressed with resection techniques, commissurotomy, chordal transfer, or artificial chordae. A prosthetic ring or pericardial band annuloplasty was used in case of annulus dilatation to increase valve coaptation and stabilize the repair. Intraoperative transesophageal echocardiography was performed in all patients.

\section{Postoperative Management}

Antibiotic therapy started preoperatively was continued postoperatively for 4 to 6 weeks. Anticoagulation for 2 months was indicated in patients receiving prosthetic ring annuloplasty.

\section{Follow-up}

Clinical follow-up was conducted by outpatient visits or telephone follow-up by a research nurse. Information on survival status, valverelated complications, and cardiovascular symptoms was obtained. Transthoracic echocardiography was obtained in all patients predischarge and at regular intervals during follow-up. The closing interval for the study was between November 2010 and January 2011. Clinical and echocardiographic follow-ups were $99 \%$ and $86 \%$ complete, respectively. Median follow-up was 65 months (interquartile range, 24-114 months).

\section{Statistical Analyses}

Statistical analyses were performed using SAS v. 9.1 (SAS Institute, Inc, Cary, NC). Continuous data are presented as mean \pm standard deviation or median (interquartile range) for nonparametric data. Failure time data on survival, MV reoperation, repair failure (defined as MV reoperation, MR $>3+$, MV stenosis with mean gradient $>10 \mathrm{~mm} \mathrm{Hg}$ ), and valve-related events are presented using Kaplan-Meier curves. Patients with and without patch repair techniques were compared for the different long-term outcomes using log-rank testing. Univariable analysis using log-rank test was performed to identify predictors of long-term mortality and repair failure.

\section{RESULTS}

\section{Early Outcomes}

Hospital mortality was $16 \%(\mathrm{n}=17)$. Causes of death were congestive heart failure $(\mathrm{n}=6)$, respiratory failure $(n=3)$, neurologic $(n=3)$, sepsis $(n=2)$, cardiac arrest 
TABLE 1. Preoperative patient characteristics and intraoperative data

\begin{tabular}{|c|c|}
\hline Preoperative patient characteristics & $\mathbf{N}=109(\%)$ \\
\hline Age (mean $\pm \mathrm{SD}$, range) & $59 \pm 11(19-85)$ \\
\hline Male gender & $74(68)$ \\
\hline History of cardiac surgery & $18(17)$ \\
\hline Diabetes mellitus & $19(17)$ \\
\hline Renal failure* & $19(17)$ \\
\hline Preoperative hemodialysis & $7(6)$ \\
\hline Septic emboli & $35(32)$ \\
\hline Cerebrovascular emboli & $21(19)$ \\
\hline $\mathrm{NYHA} \geq \mathrm{III}$ & $38(35)$ \\
\hline Cardiogenic shock & $16(15)$ \\
\hline Uncontrolled/persistent sepsis & $19(17)$ \\
\hline \multicolumn{2}{|l|}{ MR } \\
\hline Grade 1 & $13(12)$ \\
\hline Grade 2 & $26(24)$ \\
\hline Grade $\geq 3$ & $70(64)$ \\
\hline Vegetation & $89(82)$ \\
\hline Abscess and perivalvular extension $\dagger$ & $31(28)$ \\
\hline Multiple valve endocarditis $\ddagger$ & $26(24)$ \\
\hline \multicolumn{2}{|l|}{ Bacteriology } \\
\hline Streptococcus species & $41(38)$ \\
\hline Staphylococcus species & $31(28)$ \\
\hline Other species & $24(22)$ \\
\hline Negative cultures & $13(12)$ \\
\hline \multicolumn{2}{|l|}{ Operative findings on the MV } \\
\hline Posterior leaflet lesion & $39(36)$ \\
\hline Anterior leaflet lesion & $19(17)$ \\
\hline Bileaflet lesion & $28(26)$ \\
\hline Posterolateral commissure lesion & $16(15)$ \\
\hline Anteromedial commissure lesion & $7(6)$ \\
\hline Abscess and perivalvular extension & $24(22)$ \\
\hline MV disease other than infection $\S$ & $49(45)$ \\
\hline \multicolumn{2}{|l|}{ Operative techniques } \\
\hline \multicolumn{2}{|l|}{ MV repair techniques (without patch) $\|$} \\
\hline Quadrangular/triangular resection & $49(45)$ \\
\hline Resection + sliding plasty & $24(22)$ \\
\hline $\begin{array}{l}\text { Artificial chordae (Gore-Tex CV5; WL } \\
\text { Gore \& Associates, Inc, Flagstaff, Ariz) }\end{array}$ & $21(19)$ \\
\hline Native chordae tendineae transfer & $12(11)$ \\
\hline Commissurotomy & $3(3)$ \\
\hline Papillary muscle plication & $2(2)$ \\
\hline MV repair with patch techniques & $67(61)$ \\
\hline Autologous or bovine pericardial patch & $51(47)$ \\
\hline Tricuspid valve autograft & $8(7)$ \\
\hline Flip-over technique & $7(6)$ \\
\hline Partial MV homograft & $5(5)$ \\
\hline MV annuloplasty & $73(67)$ \\
\hline Prosthetic ring $₫$ & $60(55)$ \\
\hline \multicolumn{2}{|l|}{ Ring size } \\
\hline 26 & $4(4)$ \\
\hline 28 & $10(9)$ \\
\hline 30 & $18(17)$ \\
\hline 32 & $17(16)$ \\
\hline 34 & $5(5)$ \\
\hline 36 & $3(3)$ \\
\hline
\end{tabular}

TABLE 1. Continued

\begin{tabular}{|c|c|}
\hline Preoperative patient characteristics & $\mathbf{N}=109(\%)$ \\
\hline Peric & \\
\hline $\mathrm{SD})$ & 9 \\
\hline$\pm \mathrm{SD})$ & 16 \\
\hline Associated procedure\# & \\
\hline \multicolumn{2}{|c|}{$\begin{array}{l}N Y H A \text {, New York Heart Association; } S D, \text { standard deviation; } M R \text {, mitral regurgita- } \\
\text { tion. *Serum creatinine serum level }>2 \mathrm{mg} / \mathrm{dL} \text {. } \dagger \text { Mitral or aortic valve abscess. } \\
\ddagger \text { Includes aortic valve }(\mathrm{n}=23) \text { or tricuspid valve }(\mathrm{n}=2) \text {. } \S \text { Includes myxomatous dis- } \\
\text { ease }(\mathrm{n}=19) \text {, calcification }(\mathrm{n}=11) \text {, Barlow disease }(\mathrm{n}=7) \text {, rheumatic disease }(\mathrm{n}= \\
6 \text { ), previous MV repair }(5) \text {, and congenital disease }(\mathrm{n}=1) \text {. } \| \text { More than } 1 \text { technique } \\
\text { was generally performed in a single patient, and no-patch techniques may coexist } \\
\text { with patch techniques. } \uparrow \text { Includes rigid ring }(\mathrm{n}=54) \text { (Carpentier Edwards Physio } \\
\text { ring, Edwards Lifesciences Corp, Irvine, Calif, } \mathrm{n}=43 \text {; CG Future ring, Medtronic } \\
\text { Inc, Minneapolis, Minn, } \mathrm{n}=4 \text {; Saddle ring, St Jude Medical Inc, St Paul, Minn, } \mathrm{n} \\
=4 \text {; unknown brand, } \mathrm{n}=3 \text { ) and supple ring (Duran AnCore ring (Medtronic Inc, } \\
\mathrm{n}=6 \text { ). \#Includes aortic valve replacement or repair }(\mathrm{n}=17) \text {, aortic annulus repair } \\
\text { with patch and aortic valve replacement }(\mathrm{n}=9) \text {, tricuspid valve repair }(\mathrm{n}=12) \text {, } \\
\text { and coronary artery bypass grafting }(\mathrm{n}=12) \text {. }\end{array}$} \\
\hline
\end{tabular}

$(\mathrm{n}=2)$, and multiple organ failure $(\mathrm{n}=1)$. Reoperation for bleeding occurred in $11 \%$ of patients $(n=12)$, a permanent pacemaker was implanted in $3.7 \%$ of patients $(\mathrm{n}=4)$, reoperation for superficial and deep sternal infection was performed in $2.8 \%$ of patients $(n=3)$, and a new cerebrovascular event occurred in $4.6 \%$ of patients $(n=$ 5). MV reoperation was necessary in 5 patients $(4.6 \%)$ (4 replacements, 1 re-repair). The mechanisms of repair failure were suture dehiscence in 4 patients and systolic anterior motion in 1 patient. Suture dehiscence occurred after pericardial patch repair $(n=2)$, quadrangular resection $(n=1)$, and tricuspid autograft patch repair $(n=1)$. After this last case (the first of our tricuspid autograft series), artificial chordae have systematically been used to relieve tension of tricuspid papillary muscle suture. Early MV reoperation occurred in $6 \%$ of patients after patch repair and in $2.4 \%$ of patients after no-patch repair $(P=.7)$. In 1 patient, the repair failure (patch dehiscence) was related to an uncontrolled Staphylococcus aureus sepsis leading to mediastinitis and recurrent endocarditis on postoperative day 6.

\section{Late Outcomes}

At 8 years, overall survival was $62 \% \pm 10 \%$. Overall survival was similar in patients with and without patch repair $(P=.5)$ (Figure 1, $A)$. Freedom from late cardiac death was $85 \% \pm 10 \%$ at 8 years. During the follow-up period, 6 patients underwent MV reoperation for recurrent MR; of these, 3 had MV replacement and 3 had MV rerepair. At 8 years, freedom from $\mathrm{MV}$ reoperation was $89 \% \pm 8 \%$ and freedom from MV replacement was $92 \% \pm 8 \%$. Freedom from MV reoperation was not significantly different between patients with or without patch repair $(88 \% \pm 10 \%$ vs $90 \% \pm 10 \% ; P=.2$; Figure $1, B)$; however, freedom from MV replacement was significantly lower in patients with patch repair $(87 \% \pm 10 \%$ vs $100 \%, \mathrm{P}=.03)$. At last echocardiographic follow-up, 

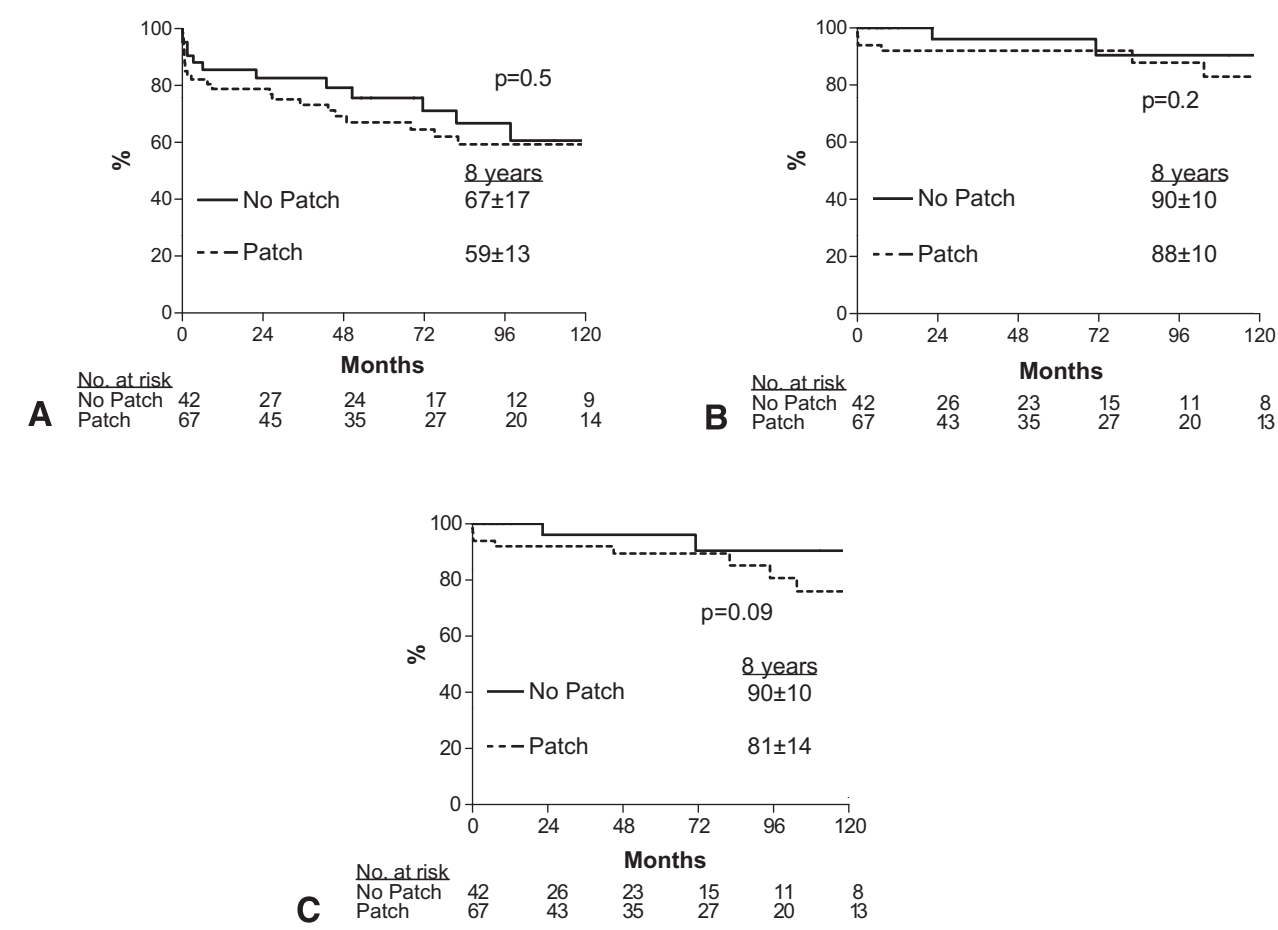

FIGURE 1. Kaplan-Meier actuarial survival curves comparing patients with or without patch repair. A, Overall survival including hospital mortality $(P=.5)$. $\mathrm{B}$, Freedom from MV reoperation $(P=.2)$. C, Freedom from MV repair failure $(P=.09)$.

1 patient had severe MR and 2 patients had a mean MV gradient greater than $10 \mathrm{~mm} \mathrm{Hg}$. Freedom from MV repair failure at 8 years was $84 \% \pm 10 \%$ with a nonsignificant trend in favor of the patients without patch repair $(81 \% \pm$ $14 \%$ vs $90 \% \pm 10 \% ; \mathrm{P}=.09$ ) (Figure $1, C$ ). In patients with patch repair, freedom from MV repair failure was higher in leaflet perforation repair than in free margin repair or MV annulus repair ( $94 \%$ vs $72 \%$ vs $84 \%, P=.5)$. Recurrent IE occurred in 1 patient with patch repair. At 8 years, freedom from endocarditis recurrence was $99 \% \pm$ $2 \%$. The linearized rate of endocarditis recurrence was $0.3 \%$ per patient-year. A thromboembolic or bleeding event occurred in 6 patients ( 4 strokes, 2 bleeding). At 8 years, freedom from thromboembolic or bleeding was $90 \% \pm 8 \%$ with no significant difference between patients with and without patch repair $(\mathrm{P}=.8)$. The linearized rate of thromboembolic or bleeding event was $1 \%$ per patient-year. At last follow-up contact, all patients were in New York Heart Association class I $(83 \%)$ or II $(17 \%)$.

\section{Univariable Predictors of Mortality and Repair Failure}

In the univariate analysis, the most significant predictors of long-term mortality were advanced age ( $>70$ years) $(P<$ .0001), perivalvular extension (ie, abscess or fistula) $(P=$ $.002)$, diabetes mellitus $(P=.0002)$, and renal failure (plasma creatinine level $<2 \mathrm{mg} / \mathrm{dL})(P=.04)$. In terms of predictors of repair failure, only renal failure $(P=.035)$ and perivalvular extension $(P=.033)$ were significant. Patch use and preexisting calcified or rheumatic valve disease showed nonsignificant trends toward repair failure $(P=.09$ for both $)$.

\section{DISCUSSION}

In this 2-decade retrospective study of MV repair for active IE, we showed that the use of a repair-oriented surgical approach achieves a repair rate of $80 \%$ with acceptable morbidity and good long-term results. In $60 \%$ of the cases, patch repairs were used to restore MV function, and the durability of those techniques approximates the durability obtained with no-patch reconstructive techniques.

Our specific approach to active IE has apparently not reduced mortality in comparison with a less aggressive reconstructive surgical approach. ${ }^{7,8}$ This finding may be explained by the fact that in IE, the potential survival benefit conferred by MV repair is negated by disease-related factors, such as advanced age, associated comorbidities, and perivalvular extension, which are all strong predictors of mortality. However, as already reported by Feringa and colleagues ${ }^{3}$ in a meta-analysis comparing MV repair with replacement in IE, we confirm the benefit of MV repair in terms of low rates of cerebrovascular event and recurrent IE.

With respect to the durability of MV repairs, our results show that for patients undergoing repair with the no-patch 
techniques classically used in degenerative MV disease, the durability is similar to the long-term results reported in MV repair for degenerative disease. ${ }^{9,10}$ The use of a patch for leaflet extension or annulus repair was associated with a somewhat higher long-term failure rate in comparison with the no-patch techniques, but the difference did not reach statistical significance. Reasons for the relatively good outcomes of patch repair techniques may be that we used a patch technique for localized repair only, respecting the native tissue as much as possible, and that we adapted the type of patch to the lesion as described in our surgical techniques. Of note, patch-related durability is also influenced by the type of patch and the way the patch is used. For a pericardial patch, better durability is suggested in patients in whom it was used to treat leaflet perforation. Therefore, leaflet free margin, even a thin band, should be preserved whenever possible. The autologous transfer from posterior to anterior leaflet, the flip-over technique, has shown no failure; a wider use of this technique may be an option to improve the results of anterior free margin repair.

Suture dehiscence observed in early failures is likely related to excessive tension on the sutured tissues. There are 2 potential technical solutions to this problem: to reduce the tension on the suture and to make the suture stronger. For example, a more aggressive annular reduction in addition to quadrangular resection will reduce tension on leaflet approximation. Additional artificial chordae or chordae transfer will reduce tension on a free margin patch or a tricuspid autograft papillary muscle suture. On the other hand, reinforcement of the suture itself can be done by suturing in healthy tissues (ie, non-inflammatory tissues), by taking more tissue in the suture (ie, larger bites), or by adding single stitches over a running suture.

\section{CONCLUSIONS}

In active MV endocarditis, a repair-oriented surgical approach, including early surgery and liberal use of biological patch techniques, achieves a repair rate of $80 \%$ with acceptable morbidity and good long-term results. Patch techniques were used in $60 \%$ of the cases and offer a durability rate that approximates the rate obtained with no-patch reconstructive techniques.

\section{References}

1. Hill EE, Herijgers P, Herregods MC, Peetermans WE. Evolving trends in infective endocarditis. Clin Microbiol Infect. 2006;12:5-12.

2. Dreyfus G, Serraf A, Jebara VA, Deloche A, Chauvaud S, Couetil JP, et al. Valve repair in acute endocarditis. Ann Thorac Surg. 1990;49:706-13.

3. Feringa HH, Shaw LJ, Poldermans D, Hoeks S, van der Wall EE, Dion RA, et al Mitral valve repair and replacement in endocarditis: a systematic review of literature. Ann Thorac Surg. 2007;83:564-70.

4. de Kerchove L, Vanoverschelde JL, Poncelet A, Glineur D, Rubay J, Zech F, et al. Reconstructive surgery in active mitral valve endocarditis: feasibility, safety and durability. Eur J Cardiothoracic Surg. 2007;31:592-9.

5. Nishimura RA, Carabello BA, Faxon DP, Freed MD, Lytle BW, O'Gara PT, et al. ACC/AHA 2008 Guideline update on valvular heart disease: focused update on infective endocarditis: a report of the American College of Cardiology/American Heart Association Task Force on Practice Guidelines endorsed by the Society of Cardiovascular Anesthesiologists, Society for Cardiovascular Angiography and Interventions, and Society of Thoracic Surgeons. J Am Coll Cardiol. 2008;52: 676-85

6. Hvass U, Juliard JM, Assayag P, Laperche T, Pansard Y, Chatel D. Tricuspid autograft for mitral-valve repair. Lancet. 1996;347:659-61.

7. Musci M, Hübler M, Pasic M, Amiri A, Stein J, Siniawski H, et al. Surgery for active infective mitral valve endocarditis: a 20-year, single-center experience. J Heart Valve Dis. 2010;19:206-15.

8. Wilhelm MJ, Tavakoli R, Schneeberger K, Hörstrupp S, Reuthebuch O, Seifert B, et al. Surgical treatment of infective mitral valve endocarditis. J Heart Valve Dis. 2004;13:754-9.

9. Gillinov AM, Cosgrove DM. Mitral valve repair for degenerative disease. $J$ Heart Valve Dis. 2002;11(Suppl 1):S15-20.

10. David TE, Ivanov J, Armstrong S, Christie D, Rakowski H. A comparison of outcomes of mitral valve repair for degenerative disease with posterior, anterior, and bileaflet prolapse. J Thorac Cardiovasc Surg. 2005;130:1242-9. 